Advances in Geosciences, 2, 279-284, 2005

SRef-ID: 1680-7359/adgeo/2005-2-279

European Geosciences Union

(c) 2005 Author(s). This work is licensed

under a Creative Commons License.

\title{
New urban area flood model: a comparison with MIKE11-quasi2d
}

\author{
A. Sole ${ }^{1}$ and G. Zuccaro ${ }^{2}$ \\ ${ }^{1}$ Environmental Engineering and Physics Department, Univ. of Basilicata, via dell'Ateneo Lucano 10, 85100 Potenza, Italy \\ ${ }^{2}$ Hydrodata S.p.a., via Pomba 23, 10123 Torino, Italy
}

Received: 11 November 2004 - Revised: 19 June 2005 - Accepted: 27 June 2005 - Published: 9 August 2005

\begin{abstract}
Recent hydrogeological events have increased both public interest and that of the Scientific Community in a more accurate study of flooding in urban areas. The present project proposes a new model which offers an optimal integration of two models, one for flood wave propagation in riverbeds and the other for flooding in urban areas.
\end{abstract}

We consider it necessary to not only treat the modelling of the outflow in riverbeds and outside riverbeds.together but to integrate them thoroughly. We simulate the propagation in riverbed of the flood event with a model solving the equations of De Saint Venant with the explicit scheme at the finite differences by McCormack. The propagation outside the riverbed is simulated using an algorithm proposed by Braschi et al. (1990).

This algorithm is based on a local discretization of the urban territory, divided in a series of "tanks" and "channels". Each tank is associated with an area of an extension related to the position of the other tanks and the quantity of buildings, modelled as insurmountable obstacles.

The model facilitates the simultaneous performance of the two simulations: at each instant, the quantitiy of water overflow, depending on the piezometric level in every section, is calculated as a function of the dimensions of the weirs (the banks), assuming it passes through the critical state. Then, it is transferred to the tanks placed in the surroundings of the overflow points. Those points are the starting nodes for the propagation of the flood because they are connected to the network of tanks in which the surrounding land has been schematised.

In this paper, we present a comparison of one of the most powerful models of inundation simulation in urban and nourban areas. The field area is the city of Albenga (SV, Italy) and the simulated event is the inundation of the 1994 (return period of about 25 years).

Correspondence to: A. Sole

(sole@unibas.it)

\section{Introduction}

Recent climatatic events, which have caused crises in rivercrossed areas, have renewed interest in hydrogeological risks and methods of flood event prevention.

The complex morphology of stressed urban areas makes it difficult to apprehend the real degree of vulnerability. Hence, it is necessary to create a model in which the in-bed propagation and the out-bed inundation are interrelated in a GIS environment.

In the present paper, we propose a model that integrates the phenomenon of the in-bed propagation and the dynamic of the out-bed inundation and takes into account the diminishing of the discharge downward from an esundation point and the eventual re-entries at the end of the flood. Thus, it explains the mutual interaction between the water-course and the surrounding urban territory and it simulates the inundation event in a reasonable time.

\section{Model description}

The proposed model (Sole and Zuccaro, 2001 , 2002, 2003) is composed of several modules. They interact through an intense data exchange, until the graphical representation of the progressive advance of the flood either into the water-bed or outside is completed. These modules are:

1. the GIS module (input/output);

2. the in-bed flow module;

3. the out-bed inundation module.

The first one acquires all the information about the urban territory (such as DTM, position of squares and streets, etc....) from files obtained in a GIS environment and it is able to represent the results. The second one simulates the flood-flow into the river-bed using a numerical finite difference scheme plus a TVD scheme for the attenuation of the numerical fluctuations. The last module simulates the propagation of the flood volumes using the network schematisation. 


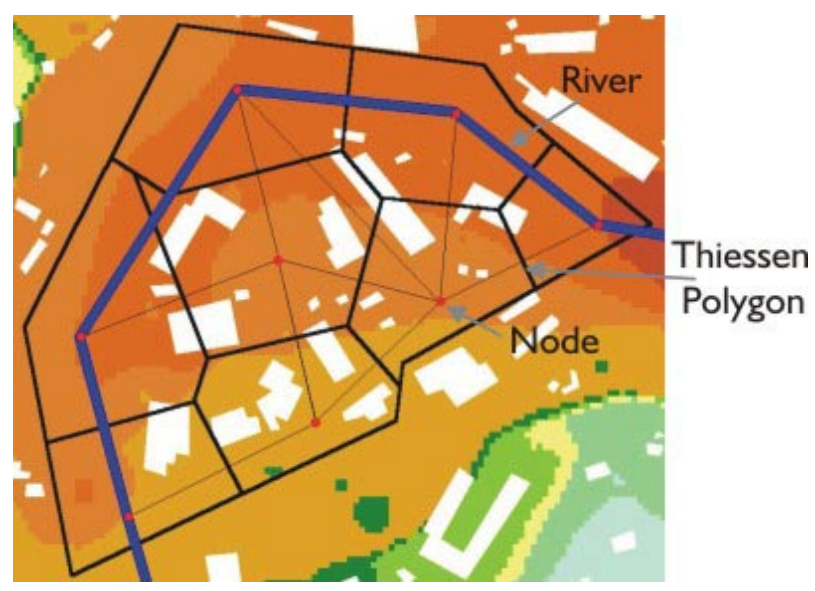

Fig. 1. Urban territory scheme.

\subsection{Functioning model scheme}

The proposed model has a graphical interface able to receive the input data necessary for the hydrodynamic simulation, in particular: the water-bed geometry, the urban territory geometry, the hydrogram, the friction factors (both in-bed and outbed) and the spatial and time integration interval. These data are stored in a database and can be modified and refreshed by an external program. Using the GIS module, the urban territory has been discretized in a series of tanks (generally in the centre of the squares) linked by channels (Fig. 1).

The tanks represent the storage capacity of a portion of urban territory. The relevant area of each tank is automatically calculated thanks to the method of Thiessen polygons.

\subsection{In-bed flow module}

The in-bed deflow module solves the equations of De Saint Venant with the explicit finite difference scheme of McCormack plus a TVD scheme (Garcìa-Navarro et al., 1992a). The equations are expressed in the following vectorial form:

$\frac{\partial \boldsymbol{U}}{\partial t}+\frac{\partial \boldsymbol{F}}{\partial x}=\boldsymbol{G}$

where " $U$ " is the vector of the unknown variables:

$\boldsymbol{U}=\left(\begin{array}{l}\Omega \\ Q\end{array}\right)$

where " $\Omega$ " is the wetted area and " $Q$ " is the discharge; " $F$ " is the vector of the "flux":

$\boldsymbol{F}=\left(\begin{array}{c}Q \\ \frac{Q^{2}}{\Omega}+g \cdot m s\end{array}\right)$

where " $g$ " is the acceleration of gravity and " $m s$ " is the static momentum; " $\boldsymbol{G}$ " is the "source" vector:

$\boldsymbol{G}=\left(\begin{array}{c}0 \\ g \cdot[m s d+\Omega \cdot(i-j)]\end{array}\right)$

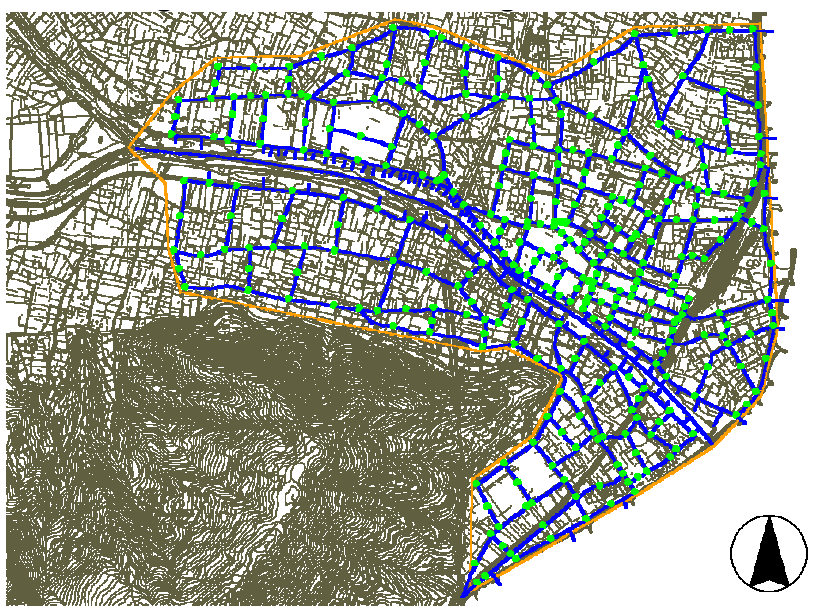

Fig. 2. Tanks and channels.

where " $m s d$ " is the longitudinal variation of the static momentum, " $i$ " is the bed slope and " $j$ " is the friction slope.

The model computes, for each time step, the values for the discharge and the wetted area for each cross section, as functions of the values assumed in the previous time step in the same section and in the two adjacent sections. When adopting the method of McCormack (Garcìa-Navarro et al., 1992a), in order to calculate the new vector " $U$ ", it is necessary to go through the "predictor" and "corrector" steps.

The user, thanks to a button on the graphical interface, can add a TVD scheme to the scheme of McCormack (GarcìaNavarro et al., 1992a; Garcìa-Navarro et al., 1992b; Hirsch, 1990; Macchione and Morelli, 1996), to reduce the numerical oscillations.

The discharge for unit length that outflows form the river is obtained from Eq. (5). This quantity has been computed whenever the piezometric level is higher than the two bank levels:

$q=k_{q} \cdot \sqrt{2 \cdot g \cdot\left(h-z_{l x}\right)^{3}}+k_{q} \cdot \sqrt{2 \cdot g \cdot\left(h-z_{r x}\right)^{3}}$

where " $k_{q}$ " is the discharge coefficient (equal to 0.385 ), " $h$ " is the piezometric level and " $z_{l x}$ " and " $z_{r x}$ " are the bank levels of the left and right respectively.

The first upstream boundary condition is due to the hydrogram and the other is calculated in one of the sequent methods:

- in case of local subcritical flow, using the method of characteristics and, in particular, the "negative" characteristic;

- in case of local supercritical flow, using a Q-h relation.

At the downstream end of the river, the first condition is determined using the method of the characteristics and, in particular, the "positive" curve that proceeds in the same direction of the flow, but the second one is determined, like the first cross section upstream, in function of the local regime of the current. 


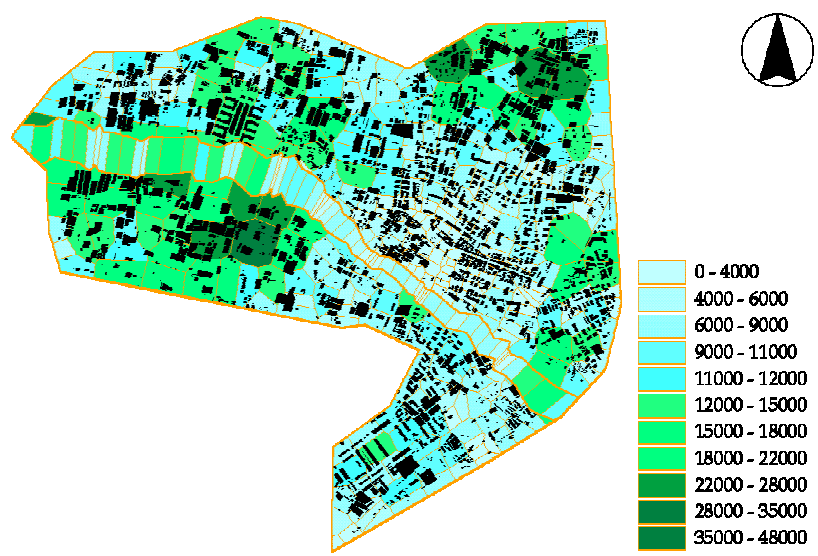

Fig. 3. Evaluation of clean areas.

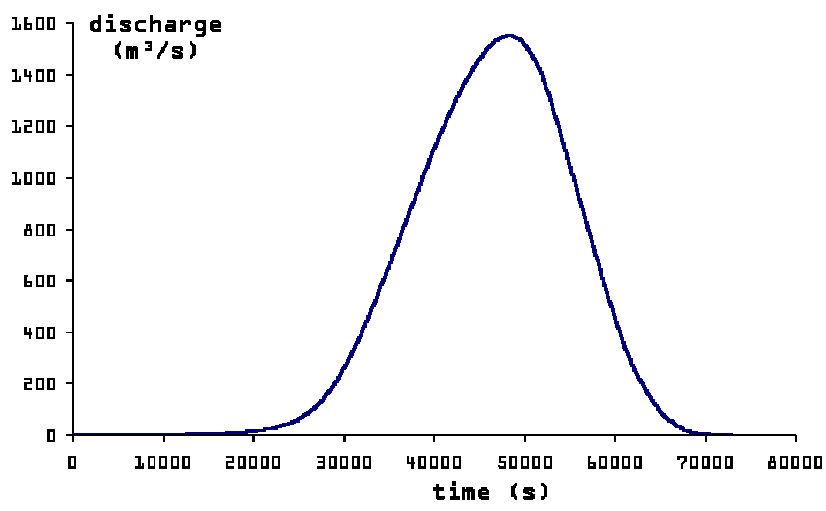

Fig. 4. Hydrogram of the studied event.

\subsection{Out-bed inundation module}

The out-bed inundation module simulates the flow of the flood volumes outflowing from the river-bed using an algorithm due to Braschi et al. (1990) and developed by the CIMA - Interuniversitary Environmental Monitoring Research Centre (Boni et al., 2002; Braschi et al., 1990; Crosta et al., 2001).

This module verifies the existence for each node with a no-null water depth, of one or more connected nodes with a minor piezometric level. If such nodes exist, it calculates the exchange discharge with the following equation:

$Q_{12}=\chi \cdot B \cdot \sqrt{\frac{\left(z_{1}+y_{1}\right)-\left(z_{2}+y_{2}\right)}{L_{12}} \cdot\left(\frac{y_{1}+y_{2}}{2}\right)^{3}}$

where " $\chi$ " is the Chezy friction factor, " $B$ " is the channel width and " $y$ " and " $z$ " represent the water depth and the height on the sea of the generic nodes 1 and 2 .

The out- and in-going volumes are functions of all the exchange discharges. Analogously, for all the time steps, the module is able to calculate the water depths for each node and to delimit the inundated areas.
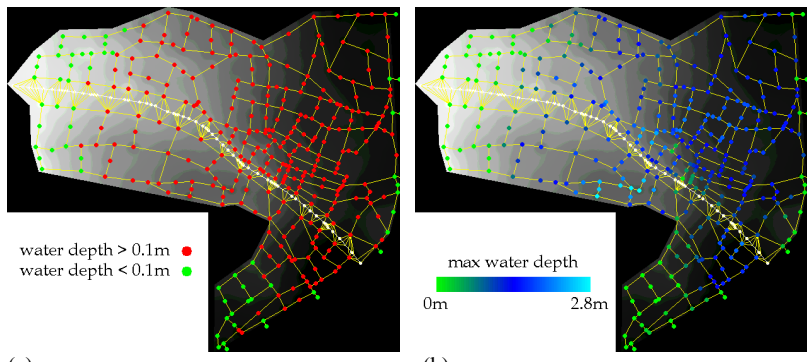

(b)

Fig. 5. Inundated area extension and maximum water depths.

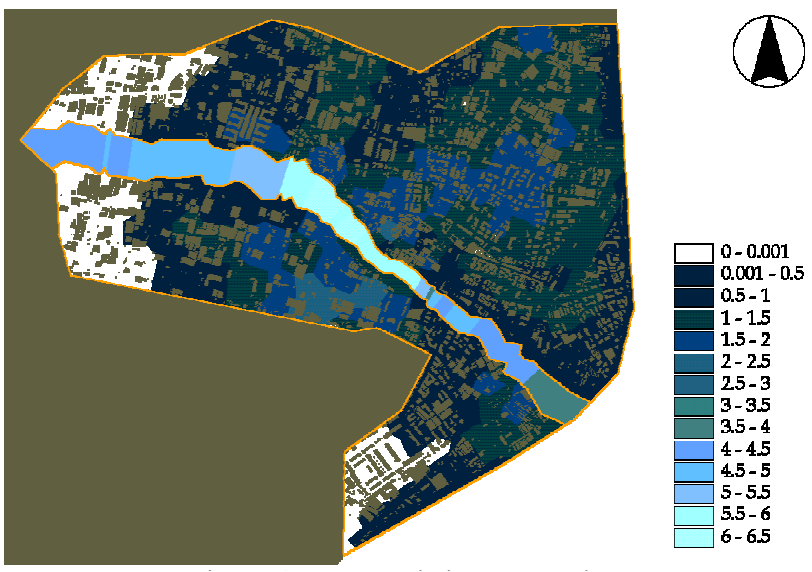

Fig. 6. Inundation map and maximum water depths.

\section{Model test}

In the absence of observed data, the test phase was carried out $t$ by a comparison with a commercial model: the MIKE 11 model (Danish Hydraulic Institute Water \& Environment) (DHI, year?).

The considered event occurred, in 1994, in the city of Albenga (SV, Italy), on the Centa river, which has been known since the Roman age for its tendency to overflow. In this case we know the inundated area extension, but not the maximum water depth in some points of the urban territory.

To simulate the flood propagation inside the potentially affected area, we set a series of representative points of the storing capacity of the open spaces. These points, as shown in Fig. 2, are connected both to each other and to the main river by several rectangular channels describing the road network.

We compute the dimension of the relevant area, for each node, with the method of Thiessen (par. 2), thereafter we subtract from it the block of the buildings to obtain the clean area that represents the store capacity (Fig. 3).

The hydrogram (Fig. 4), rebounded by CIMA, corresponds to a flood event with a return period of about 25 years, a duration of $20 \mathrm{~h}$ and a peak discharge of $1600 \mathrm{~m}^{3} / \mathrm{s}$. In the fluvial sections, also supplied by the CIMA, there is a bridge which causes a narrowing of the section but there is no evidence of hydraulic work. 


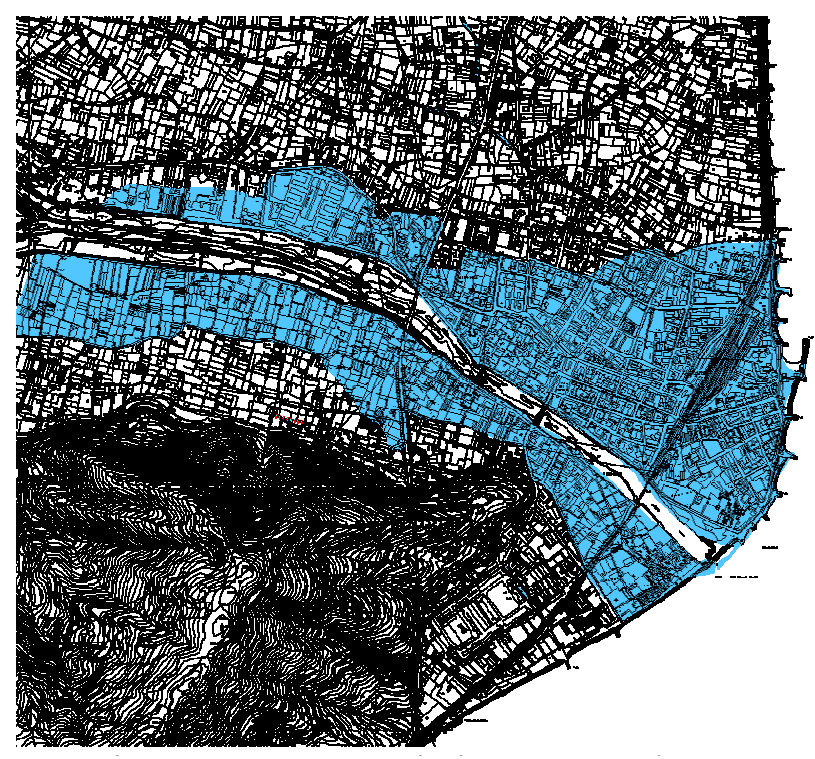

Fig. 7. Urban areas historically subject to inundation.
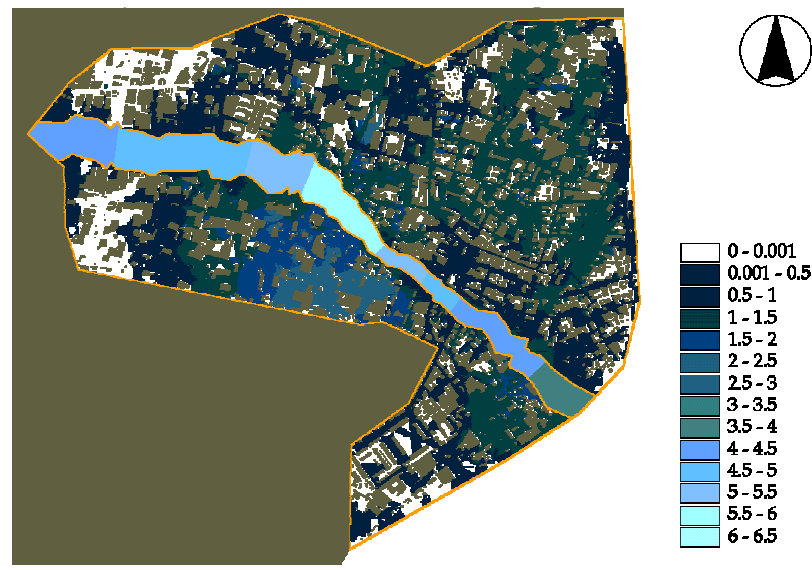

Fig. 8. Inundation map and maximum water depths according to MIKE 11 - MIKE 11 GIS model.

We report the following results of the simulations: the extension of the inundated area (Fig. 5a), the water depth for each time step and for each node and the maximum water depth for each node (Fig. 5b).

Figure 6 represents the inundation map, obtained by interpolation of the water depth in each node, and indicates the maximum values of the water depth during the whole simulation.

The biggest inundations occur in the central section of the water course under examination, coinciding with the position of the bridge where the bed narrows and the banks are relatively lower.

Other inundations take place in the final part of the water course due to significantly reduced bank levels,particularly on the right side, in the mouth area .

Figure 7 is a map of the areas historically subject to inundation.A comparison with Figs. 5 and 6 reveals that the

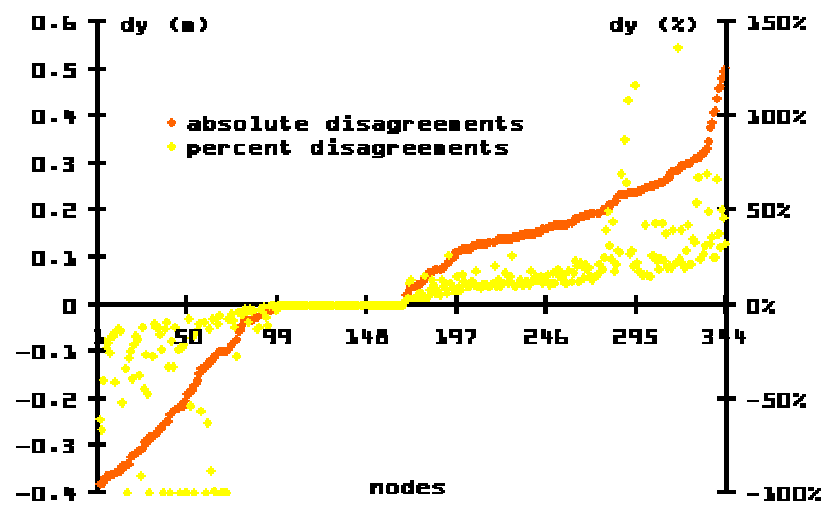

Fig. 9. Absolute and percent disagreement between the two models.

model has produced an overestimation of the extension of the flooded area which, however, refers to an event with a 20 year return period, and thus inferior to the event under consideration. In the absence of other historical data we have utilized the MIKE model 11 together with the MIKE 11 GIS as a "model of reference" for the validation of the proposed model. This model facilitates calculations of flood propagation in urban areas in quasi-bidimensional modality.

The same input hydrograph was used for the test as that utilized in Fig. 4.

The connections between the water-bed and the road network are modelled as "link channels", more precisely as a series of short and wide-width channels with this $Q$ - $h$ relation:

$\frac{Q}{L}=C_{q} \cdot Y \cdot \sqrt{2 \cdot g \cdot Y}$

where " $Q$ " is the discharge, " $L$ " is the channel width, " $C_{q}$ " is the discharge coefficient, " $g$ " is the acceleration of gravity and " $Y$ " is the water depth.

Figure 8 shows the maximum water depths according to the MIKE 11 simulation and after the interpolation of the piezometric levels made by MIKE 11 GIS.

Differences in results were observed between the in-bed module of the proposed model and MIKE 11 as well as between the out -bed module and the coupled MIKE 11 MIKE 11 GIS model. In the first case maximum water depth differences of $8 \%$ were observed in the main inundation area. In the second case, the differences between the two series of water depths, depicted in Fig. 9, are ordered in increasing size and are related to the corresponding percent differences. It can be noted that, near the greater disagreements (in absolute value), the percent differences are quite small. Figures $10 \mathrm{a}$ and $\mathrm{b}$ show this kind of disagreement in a planimetric manner.

It is possible to observe an exceed variation on the leftside of the water-course and a negative variation on the right. The positive disagreement is certainly due to the differences (positive) of the maximum piezometric level inside the waterbed. The negative ones, instead, are negligible with respect 


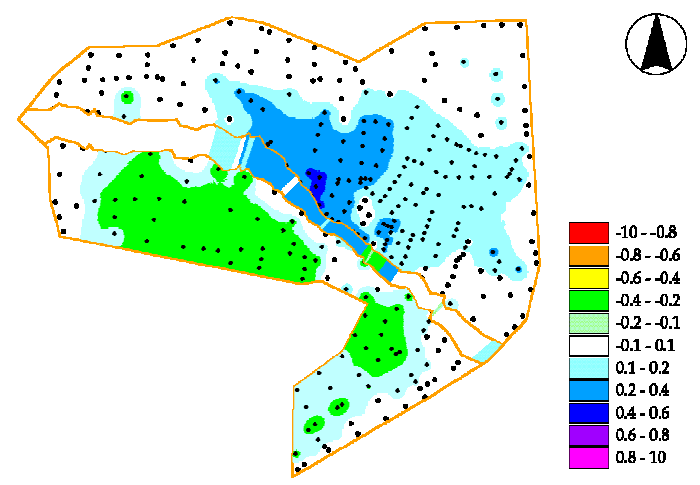

(a)

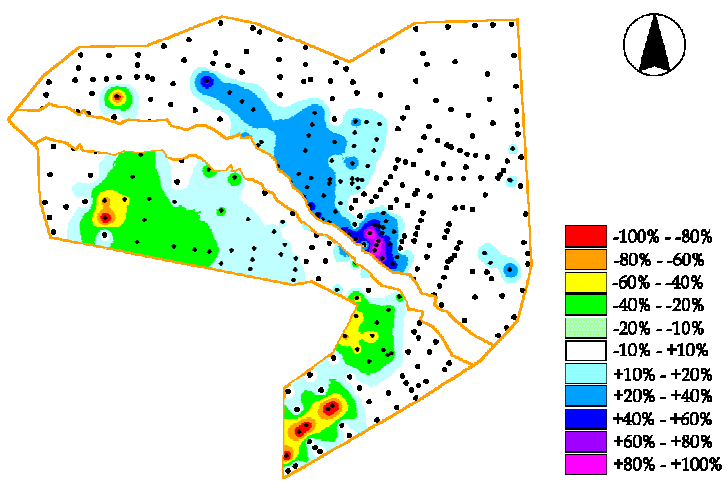

(b)

Fig. 10. Absolute and percent disagreement between the two models.

to the water depth in right areas: they are about $30 \mathrm{~cm}$, but the water depth is about $2 \mathrm{~m}$.

As highlighted in the planimetric representation (Fig. 10b), in right-hand areas the percent disagreements are about $15 \%$, while at the west boundary of the interested area the percent and absolute differences are quite relevant. The difference is due to a negative variation in the calculation of the maximum water depth into the river near the same area. By simply looking the left-side area, it is possible to observe that the percent disagreements are relevant only for a limited number of points beside the Centa river. The percent differences on the whole river, though quite small (less than 8\%), induces greater differences into the urban areas.

Figure 11 shows a part of the digital urban terrain model and the inundation simulated by the two model (MIKE 11 in cyan, proposed model in green). We register the maximum discrepancy in the involved areas. The height of the buildings is fixed at $3 \mathrm{~m}$ to appreciate also the entity of these discrepancies in relation to a base height.

\section{Conclusions}

The proposed model has the advantage of using a quasibidimensional approach for the simulation of flood propagation in urban areas. The synchronic functioning of the inand out-bed propagation modules facilitates the estimation of the inundation map in a more precise way by taking into account the re-entries inside the water-bed of part of esundated volumes and reducing the computational time. The use of the model of Braschi et al. (1990) seems particularly suitable for the schematisation of the urban texture and allows us to reach an optimum compromise between the simplicity of the model and the level of details.

The out-bed inundation module is based on a steady state equation (thus, it is subject to improvement), but can correctly reproduce the flood propagation dynamic in a complex territory like a town. Moreover, the in-bed deflow propagation module exhibits good reliability and robustness, espe-

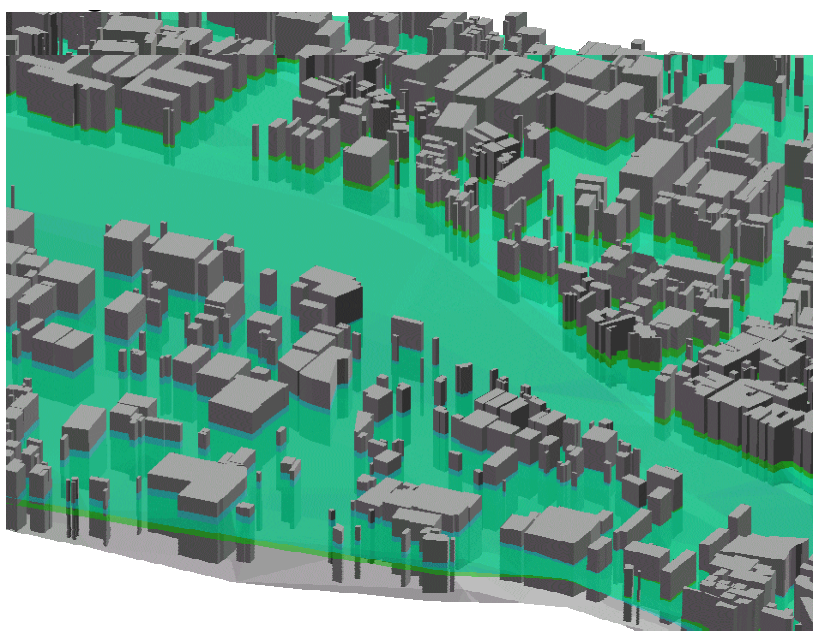

Fig. 11. Part of the inundation maps.

cially when dealing with hydraulic discontinuities and abrupt discharge or geometry variations. Therefore, the proposed model has good power to simulate the flood propagation either in- or out-bed in the surrounding urban territory.

The differences between the proposed model and the coupledMIKE 11 - MIKE 11 GIS are probably due to the differences between the two in - bed hydrodynamic propogation models as well as to a different flow modality in the channels which form the urban area.The first difference is probably a result of the different forms of interpolation of the sections using the two numeric models, as shown in Fig. 12 (Sole and Zuccaro, 2002, 2003).

In the propogation phase of the urban area the utilization of the Eq. (5) in the proposed model is an obvious limit which we are endeavouring to overcome.

However, we need to proceed cautiously and make further comparisons of the results of the model with observed data.

Edited by: L. Ferraris

Reviewed by: anonymous referees 


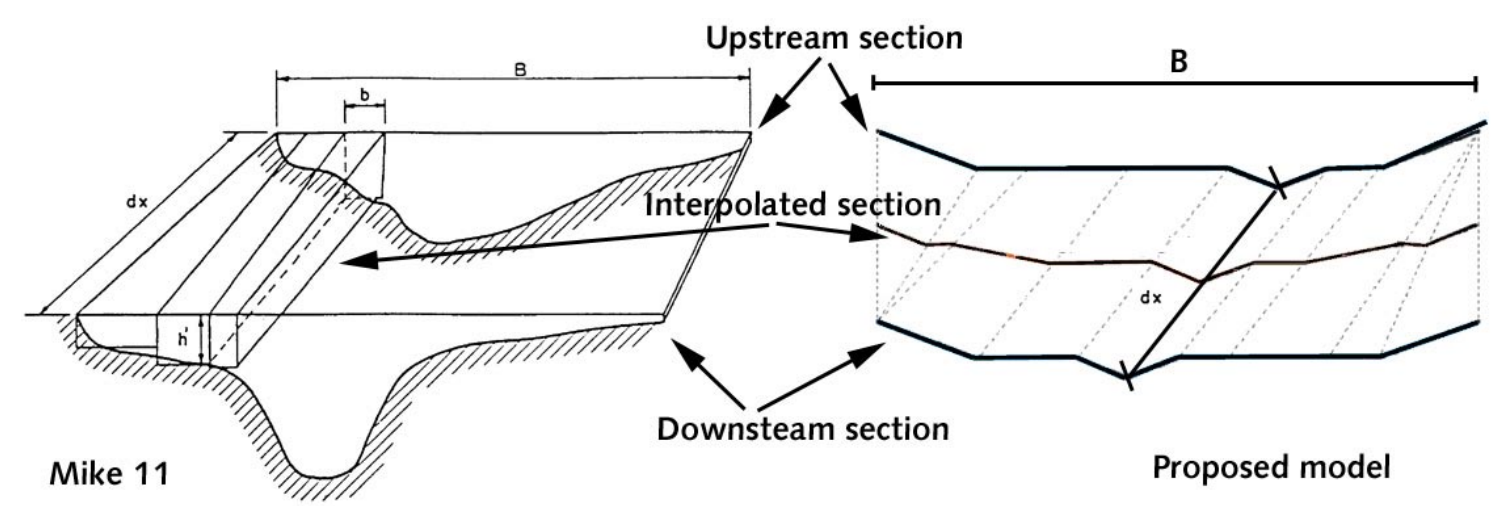

Fig. 12. Comparison of different interpolation methods of cross sections.

\section{References}

Boni, G., Crosta, A., Laverneda, S., Roth, G., Taramasso, A. C., and Versace, C.: U-flood ("urban flood") modello di propagazione delle piene in ambiente urbano, $28^{\circ}$ Convegno di Idraulica e Costruzioni idrauliche, Potenza, 16-19 Settembre 2002.

Braschi G., Gallati, M., and Natale, L.: La simulazione delle inondazioni in ambiente urbano, CNR-GNDCI, 1990.

Crosta, A., Laverneda, S., Roth, G., Siccardi, F., and Versace, C.: Implementazione del modello di propagazione dell' onda di piena in ambiente urbano relativo al piano comunale da rischio idrogeologico del comune di Genova, CIMA, October 2001.

DHI: Mike 11 version 3.11 - General Reference manual, Scientific Documentation, Danish Hydraulic Institute, 2003.

Garcìa-Navarro, P., Alcrudo, F., and Saviron, J. M.: 1-D openchannel flow simulation using TVD-McCormack scheme, J. Hydr. Eng., 118, 10, 1359-1372, October, 1992a.

Garcìa-Navarro, P. and Saviron, J. M.: McCormack' s method for the numerical simulation of one-dimensional discontinuous unsteady open channel flow, J. Hydr. Res., 30, 1, 95-105, 1992 b.
Hirsch, C.: Numerical computation of internal and external flows - volume 2: Computational methods for inviscid and viscous flows, John Wiley \& Sons, 1990.

Macchione, F. and Morelli, M. A.: Propagazione delle piene conseguenti alla rottura di sbarramenti murari, $18^{\circ}$ Corso di aggiornamento in Tecniche per la difesa dall' inquinamento, a cura di G. Frega, Editoriale Bios, Cosenza, 1996.

Marchi, E. and Rubatta, A.: Meccanica dei fluidi, UTET, 1981.

Sole, A. and Zuccaro, G.: Flooding modelling, 3rd EGS Plinius Conference on Mediterranean Storms, 1-3 Ottobre 2001, Baja Sardinia, Abstr. No. 27, 2001.

Sole, A. and Zuccaro, G.: Urban areas flooding modelling, in: Risk Analysis III, edited by: Brebbia, C. A., WIT Press Southampton UK, 521-530, 15 pp., 2002.

Sole, A. and Zuccaro, G.: Comparison between open channel flow models in natural rivers, in: River Basin Management, edited by: Brebbia, C. A., WIT Press Southampton UK, 66-768, 2003. 